\title{
Effect of soluble calcium on the renneting properties of casein micelles as measured by rheology and diffusing wave spectroscopy
}

\author{
S. Sandra, ${ }^{1}$ M. Ho, M. Alexander, and M. Corredig \\ Food Science Department, University of Guelph, Guelph, Ontario, Canada, N1G 2W1
}

\begin{abstract}
Addition of calcium chloride to milk has positive effects on cheese-making because it decreases coagulation time, creates firmer gels, and increases curd yield. Although addition of calcium chloride is a widely used industrial practice, the effect of soluble calcium on the preliminary stages of gelation is not fully understood. In addition, it is not known whether the manner of addition and equilibration of the soluble calcium would affect the rennetability of the casein micelles. Therefore, the aim of this paper was to study the details of the coagulation behavior of casein micelles in the presence of additional calcium, and to elucidate whether the manner in which this cation is added (directly as calcium chloride or by gradual exchange through dialysis) affects the functionality of the micelles. Calcium was added as $\mathrm{CaCl}_{2}$ ( $1 \mathrm{~m} M$ final added concentration) directly to skim milk or indirectly using dialysis against 50 volumes of milk. Additional soluble calcium did not affect the primary phase of the renneting reaction, as demonstrated by the analysis of the casein macropeptide (CMP) released in solution; however, it shortened the coagulation time of the micelles and increased the firmness of the gel. The turbidity parameter of samples with or without calcium showed that similar amounts of CMP were needed for particle interactions to commence. However, the amount of CMP released at the point of gelation, as indicated by rheology, was lesser for samples with added calcium, which can be attributed to a greater extent of calcium bridging on the surface or between micelles. The results also showed that the manner in which calcium was presented to the micelles did not influence the mechanism of gelation.
\end{abstract}

Key words: skim milk, calcium, dialysis, rennet

Received July 8, 2011.

Accepted August 16, 2011

${ }^{1}$ Corresponding author: ssandra201013@gmail.com

\section{INTRODUCTION}

Milk is a dispersion of protein, fat, sugars, and salt in a water-based medium (Fox et al., 2000). The main protein components, the casein micelles, are roughly spherical protein (casein) aggregates between 50 and $300 \mathrm{~nm}$ (Dalgleish, 2011). These aggregates contain colloidal calcium phosphate clusters in equilibrium with soluble calcium and are highly stable by means of a polyelectrolyte "hairy" layer of protruding $\kappa$-casein, which gives the micelle steric and electrostatic stability (De Kruif and Zhulina, 1996; Holt et al., 2003). Manipulation of these hairs produces changes in the functionality of the casein micelles, a property that is exploited in the process of cheese-making by rennet (Dalgleish, 1983; Walstra, 1990).

During the process of making cheese, a specific protease is added to the milk to cleave the $\kappa$-casein on the surfaces of the casein micelles, thereby lowering the magnitude of the repulsive potential between them and triggering aggregation (Dalgleish, 1983; Lucey and Fox, 1993; Fox et al., 2000). The rennet coagulation of milk is usually divided into 3 stages. The first phase involves the enzymatic hydrolysis of the $\kappa$-casein, the second stage refers to the aggregation and sol-gel transition of the micelles (Walstra, 1990), and the third stage involves the aging, syneresis, and structural rearrangements of the formed gel (Dalgleish, 1982; Green and Grandison, 1987).

In the cheese industry, calcium chloride is usually added to milk because it improves the texture and yield of cheese curd (Wolfschoon-Pombo, 1997; Udabage et al., 2001; Landfeld et al., 2002). This practice has the effect of reducing the rennet coagulation time of the milk. The addition of calcium lowers the milk $\mathrm{pH}$, which in turn increases the rate of the enzymatic reaction (Jen and Ashworth, 1970; Bringe and Kinsella, 1986). The hydrolysis of $\kappa$-casein causes the formation of bare patches on the casein micelles and, possibly, the exposure of calcium-sensitive patches. At the same time, the free ionic $\mathrm{Ca}^{2+}$ shields the negatively charged amino acid residues, thereby reducing the overall charge of the micelle, allowing closer approach and increased aggregation (Dalgleish, 1983, 1984). The calcium bridg- 
ing between micelles increases the rate of firming and causes the formation of stiffer gels (van Hooydonk et al., 1986). There is, however, a limit to the amount of calcium that can be added. Any amount in the excess of $10 \mathrm{~m} M$ may have a negative effect on curd formation, because the excess calcium will increase the positive charges on the surface of the micelle, causing charge repulsion and weaker gels or no gelation at all (Fox et al., 2000; Udabage et al., 2001; Choi et al., 2007).

Although the overall effects of calcium addition are widely recognized and the practice is very common in cheese making, the details of how calcium affects casein aggregation are not understood (Martin et al., 2008). This research aimed to better understand the effect of calcium on the early (primary and secondary) stages of gelation. In addition to studying the direct addition of calcium, we hypothesized that a gradual addition of calcium through dialysis may further improve the renneting functionality of the micelles. To test this hypothesis, the rennet-induced coagulation of milk was observed using 2 complementary techniques, rheology and diffusing wave spectroscopy (DWS). In addition, buffering capacity and the release of casein macropeptide (CMP) over time were measured.

\section{MATERIALS AND METHODS}

\section{Sample Preparation}

Fresh milk was obtained from the Elora Dairy Research Station of the University of Guelph (Elora, ON, Canada). Sodium azide $(0.02 \% \mathrm{wt} / \mathrm{vol})$ was immediately added to the milk to prevent bacterial growth. The milk was skimmed at $6,000 \times g$ at $4^{\circ} \mathrm{C}$ for $25 \mathrm{~min}$ in a Beckman-Coulter centrifuge (model J2-21, Beckman Coulter, Mississauga, ON, Canada), followed by filtering 4 times using Whatman glass fiber filters (Fisher Scientific, Mississauga, ON, Canada). The skim milk (SM) was then placed in a refrigerator at $4^{\circ} \mathrm{C}$ until use. In selected experiments, SM was dialyzed $[\mathbf{S M}(\mathbf{D})$; Spectra/Por Dialysis Membrane Tubing, 6,000 to 8,000 Da molecular weight cut-off; Spectrum Laboratories Inc., Rancho Dominguez, CA] against 50 volumes of pasteurized skim milk (Crown Dairy, Guelph, ON, Canada) for $24 \mathrm{~h}$ at $4^{\circ} \mathrm{C}$.

For the direct addition of $\mathrm{CaCl}_{2}$ to milk, a stock solution of $1 M \mathrm{CaCl}_{2} \cdot 2 \mathrm{H}_{2} \mathrm{O}$ (Fisher Scientific, Whitby, ON, Canada) in MilliQ water was added directly to SM to reach a final added concentration of $1 \mathrm{~m} M$ in milk, and the experiments were performed within $30 \mathrm{~min}$ of the addition $[\mathbf{S M}+\mathbf{C a}(\boldsymbol{t}=\mathbf{0})]$. The sample was then left to rest in the refrigerator for $24 \mathrm{~h}[\mathbf{S M}+\mathbf{C a}(t=$ 24)]. For the dialyzed samples, a stock solution of 1 $M \mathrm{CaCl}_{2} \cdot 2 \mathrm{H}_{2} \mathrm{O}$ was added to the pooled SM (Crown
Dairy, Guelph, ON, Canada) to reach a final concentration in the milk sample (inside the dialysis tube) of 1 $\mathrm{m} M$. Dialysis was then performed as described above to obtain SM with Ca added by dialysis $[\mathbf{S M}(\mathbf{D})+\mathbf{C a}]$.

Samples were gelled using Chy-Max Ultra rennet (Chr. Hansen, Milwaukee, WI) with an average strength of $790( \pm 5 \%)$ international milk clotting units (IMCU) $/ \mathrm{mL}$. The rennet was diluted 100-fold in MilliQ water before addition to milk. Within $5 \mathrm{~min}$, the rennet was added at a final concentration of 0.034 IMCU/ $\mathrm{mL}$ to the milk, which had been preheated to $30^{\circ} \mathrm{C}$. Immediately after the addition of the enzyme, the milk was stirred for $30 \mathrm{~s}$ before the experiments were commenced.

\section{Buffering Capacity}

Milk samples $(50 \mathrm{~mL})$ were titrated from the initial $\mathrm{pH}$ of the milk ( 6.7) to $\mathrm{pH} 2.0$ by gradual addition of $200 \mu \mathrm{L}$ of $1 \mathrm{M} \mathrm{HCl}$ (at 60 -s intervals). Subsequent to the acidification, alkalinization was obtained by addition of $1 M \mathrm{NaOH}$ ( $200 \mu \mathrm{L}, 60$-s intervals) up to $\mathrm{pH}$ 11.0. The $\mathrm{pH}$ values as a function of time were automatically recorded with an Accumet $\mathrm{pH}$ meter (Fisher Scientific, Whitby, ON, Canada).

\section{Casein Macropeptide Release}

The amount of casein macropeptide (CMP) released during renneting was measured using reverse phaseHPLC (ThermoFinnigan, Burlington, Canada). After addition of rennet, each sample was divided into 2-mL aliquots and placed in a water bath at $30^{\circ} \mathrm{C}$. At designated time intervals, samples were diluted with $4 \mathrm{~mL}$ of $3 \%$ (wt/vol) TCA solution to stop the enzymatic reaction. After TCA addition, each sample was mixed and stored overnight at $4^{\circ} \mathrm{C}$. The samples were then equilibrated at room temperature, centrifuged at 4,500 $\times g$ for 15 min, using an Eppendorf centrifuge (Brinkmann Instruments Ltd., Mississauga, ON, Canada). The supernatant collected was filtered $(0.45 \mu \mathrm{m})$ and analyzed as described previously (Sandra and Dalgleish, 2007). The maximum amount of detected CMP for each sample was considered $100 \%$ release for that sample.

\section{Rennet-Induced Gelation Experiments}

A controlled-stress rheometer AR1000 (TA Instruments, New Castle, DE) was used for the rheological measurements. Immediately after the addition of rennet, $20 \mathrm{~mL}$ of the sample at $30^{\circ} \mathrm{C}$ was placed in a concentric cylinder geometry $(5,920-\mu \mathrm{m}$ fixed gap, 15 $\mathrm{mm}$ radius, $14-\mathrm{mm}$ motor outlet radius, and $42-\mathrm{mm}$ 
cylinder immersed height) at a temperature of $30^{\circ} \mathrm{C}$ controlled by an external water bath (Isotemp 3016, Fisher Scientific). A time sweep was run at controlled strain of 0.01 , frequency of $1.0 \mathrm{~Hz}$, and initial torque of $0.1 \mathrm{mN}$. The time of gelation was defined as the time when the values of storage (elastic) modulus $\left(\mathbf{G}^{\prime}\right)$ and loss (viscous) modulus $\left(\mathbf{G}^{\prime \prime}\right)$ were equal $(\tan \delta=1)$. Gel development was then monitored for $45 \mathrm{~min}$.

In addition to rheology, DWS was performed to follow the changes occurring in the diffusion coefficient and the turbidity parameter $\left(\mathbf{1} / \mathbf{l}^{*}\right)$ for the samples during renneting. The DWS laser source was a Verdi V-2 pumped Nd:YAG laser (Coherent Inc., Santa Clara, CA) with an emission wavelength of $532 \mathrm{~nm}$ set at $300 \mathrm{~mW}$ power. A volume of $1.5 \mathrm{~mL}$ of the samples containing rennet was placed into a flat-faced, 5-mm-path-length optical glass cuvette (Hellma Canada Ltd., Concord, Canada) at $30^{\circ} \mathrm{C}$. The experiments were performed as described previously (Sandra et al., 2011) using standard latex spheres of $260 \mathrm{~nm}$ diameter (Portland Duke Scientific, Palo Alto, CA) for calibration. The scattering parameters were measured at intervals of $2 \mathrm{~min}$ for $80 \mathrm{~min}$. Data were analyzed using specialized software DWS-Fit (Mediavention Inc., Guelph, ON, Canada). For an indepth description of the theory of DWS, refer to Weitz and Pine (1993).

\section{Statistical Analysis}

Experiments were carried out in triplicate on different batches of milk (from different days). Values reported are the means and standard deviations of the triplicate experiments.

\section{RESULTS AND DISCUSSION}

To determine if the addition of soluble Ca or dialysis affected the buffering capacity of the milk samples, titrations were conducted on all samples with or without added $\mathrm{CaCl}_{2}$ (Figure 1). The peak shown at $\mathrm{pH} 5.5$ was of particular importance in the context of the present research, because it relates to the casein micelles and more specifically the colloidal calcium phosphate content (Salaun et al., 2005). The peak derives from inorganic and organic phosphate ions in solution due to the solubilization of the colloidal phosphate present in the milk (Lucey et al., 1993; Salaun et al., 2005). A second peak was found around $\mathrm{pH} 4.0$ and it has been attributed to the buffering of citrate residues in the whey proteins, and aspartate, glutamate, and citrate residues in the casein micelles (Lucey et al., 1993). During alkalinization, the main peak was at $\mathrm{pH}$ of about 6.3 , when the protons were released from their bonds with the phosphate due to the more energetically stable

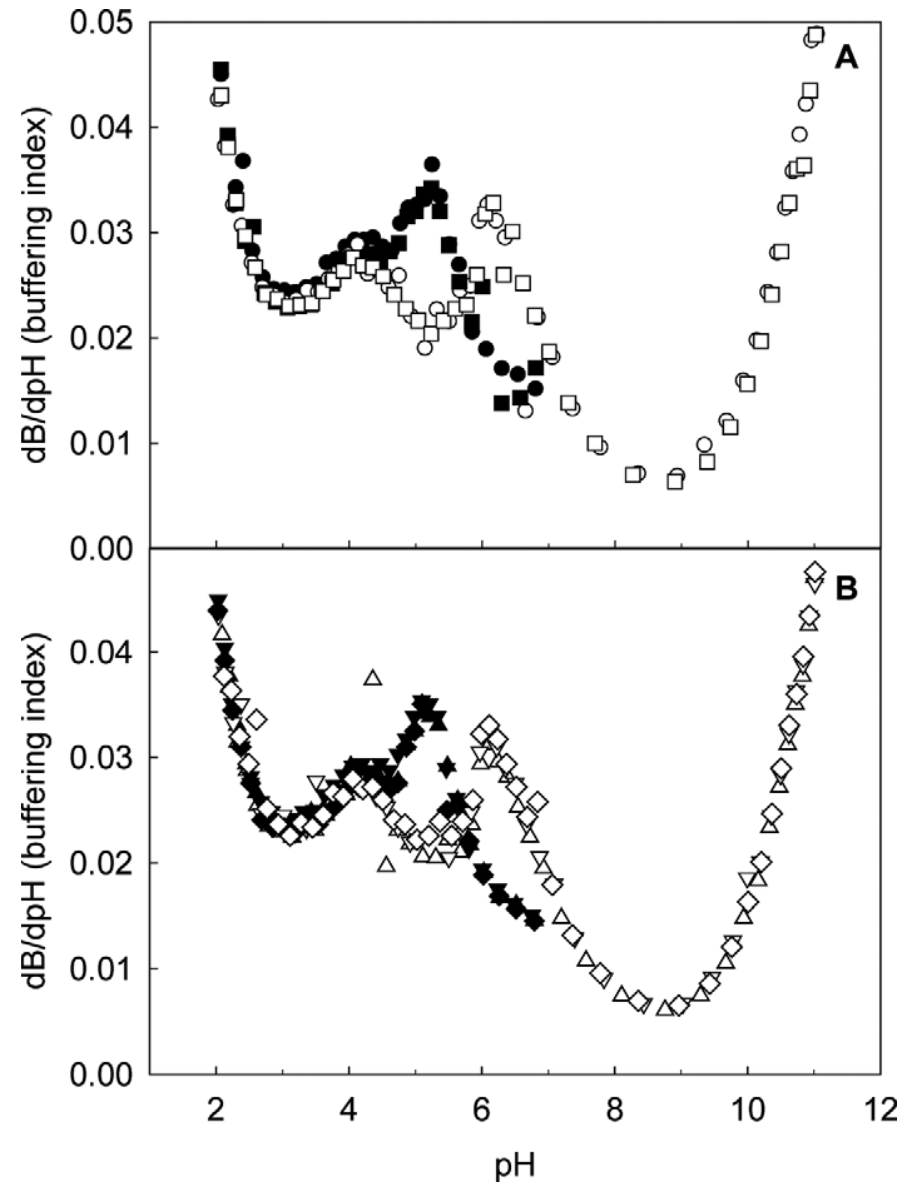

Figure 1. Buffering capacity of skim milk control (SM, circles) and dialyzed SM (squares) (A) and milk samples with calcium added directly (at time $=0$, triangles; at time $=24 \mathrm{~h}$, inverted triangles) or added using dialysis (diamonds) (B). The milk samples were acidified from the initial $\mathrm{pH}(6.7)$ to $\mathrm{pH} 2.0$ with $\mathrm{HCl}$ (filled symbols) and titrated back to $\mathrm{pH} 11.0$ with $\mathrm{NaOH}$ (empty symbols). Results are representative runs.

formation of calcium phosphate salts (Lucey et al., 1993).

It has been previously reported that the addition of $\mathrm{CaCl}_{2}$ affects the equilibrium between soluble and micellar ions, and that this may cause a shift in the buffering capacity peak to a lower $\mathrm{pH}$ during acidification due to an increase in buffering capacity of micellar phosphate and citrate (Salaun et al., 2005). Figure 1A illustrates the buffering capacity of SM and SM(D), confirming that dialysis of SM against pasteurized milk did not change this equilibrium. Likewise, the addition of $\mathrm{CaCl}_{2}$ did not show differences in the milk's buffering capacity (Figure 1B). More importantly, no differences were found between direct addition, direct addition and re-equilibration for $24 \mathrm{~h}$, or exchange using dialysis (all the curves overlap in Figure 1B). These results were in contrast to those previously reported in the literature; however, the amount of $\mathrm{CaCl}_{2}$ added in the present 
work was much lower (10 and 17.5 times, respectively) than in Udabage et al. (2000) and Guillaume et al. (2002).

Figure 2 shows the percentage of CMP released from the surface of the casein micelles by action of chymosin (compared with the maximum detected release, assigned as 100\%). This is generally regarded as the first phase of rennet coagulation. No differences were observed among all milk samples and all samples reached $90 \%$ of CMP release, the point necessary to reach the coagulation (Dalgleish, 1982; Sandra and Dalgleish, 2007), about 40 min after rennet addition. These results clearly demonstrated that the addition of $1 \mathrm{mM} \mathrm{CaCl} 2$ did not affect the primary phase of rennet aggregation. Furthermore, neither dialysis nor addition of calcium in a direct or progressive way affected the first phase of rennet aggregation of casein micelles. It has been shown that direct calcium addition (up to $10 \mathrm{~m} M$ ) did not affect the first phase of rennet action (Mehaia and Cheryan, 1983; Fox et al., 2000). On the other hand, Bringe and Kinsella (1986) showed that the first phase of a chymosin-catalyzed reaction increased with the addition of 3 to $10 \mathrm{~m} M$ calcium; however, the amount used in the present work $(1 \mathrm{mM})$ was below this range. The present results, therefore, not only confirmed the previous literature but also further suggested that equilibration time or aging for up to $24 \mathrm{~h}$ did not affect the rennet functionality of the casein surface.

To determine the changes occurring in the coagulation behavior of the casein micelles, the sol-gel transition was followed using rheology and DWS. Direct

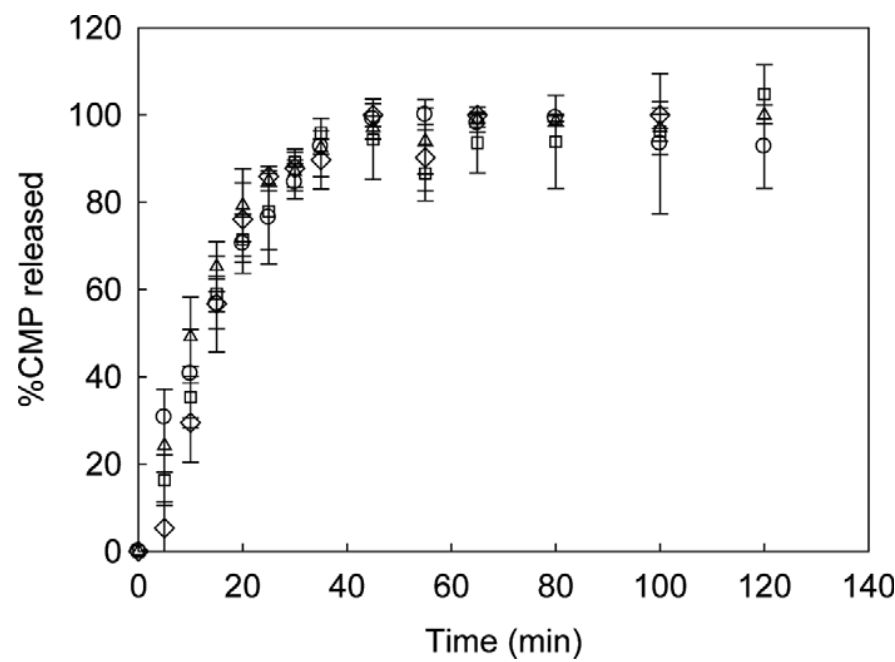

Figure 2. Casein macropeptide (CMP) released as a function of time after rennet addition: skim milk control (SM, circles), dialyzed SM (squares), and milk samples with calcium added directly (triangles) or added using dialysis (diamonds). Data represent the mean of 3 runs and error bars indicate standard deviations. Maximum amount of detected CMP was assigned $100 \%$. addition of calcium to milk shortens milk coagulation time and causes firmer gels (Solorza and Bell, 1998; Udabage et al., 2001; Landfeld et al., 2002). However, by using DWS, it is possible to follow, in situ and without dilution, the early stages of aggregation of the casein micelles, allowing for better understanding of the possible effects of soluble calcium on the rennetability of the casein micelles.

Before studying the effect of calcium, we performed control experiments to determine if dialysis of untreated skim milk against pasteurized milk caused any changes in the renneting behavior of the casein micelles. Figure 3 shows the rheological parameters $\left(\mathrm{G}^{\prime}\right.$ and $\left.\tan \delta\right)$ and those determined by DWS ( $1 / l^{*}$ and apparent radius) for SM and SM(D) after the addition of rennet. The coagulation point, determined as $\tan \delta=1$, was $53 \pm 3$ $\min$ for $\mathrm{SM}$ and $54 \pm 1 \mathrm{~min}$ for $\mathrm{SM}(\mathrm{D})$. The values of $\mathrm{G}^{\prime}$ measured 45 min after gelation were similar for both systems, as was the value of $\tan \delta$ reached at plateau (0.26; see also Table 1 for a summary of all gelation parameters). Rheological measurements (Figure 3A) demonstrated that dialysis did not change the gelation point or the development of the network structure.

Using DWS (Figure 3B), it was possible to determine if any changes occurred in the aggregation of the micelles (by following the behavior of the apparent radius) or to the optical properties of the milk (by following the behavior of the turbidity parameter). The DWS results were in agreement with those shown in Figure $3 \mathrm{~A}$, as the DWS parameters were the same for SM and $\mathrm{SM}(\mathrm{D})$. The initial value of $1 / 1^{*}$ was unchanged for SM and $\operatorname{SM}(\mathrm{D})$, revealing equal overall scattering properties. The general development of $1 / 1^{*}$ during rennetinduced gelation was also similar for both systems and in agreement with previous results (Sandra and Dalgleish, 2007). A clear upturn of $1 / 1^{*}$ was observed at around $20 \mathrm{~min}$ (see Table 1), which corresponded to approximately 70 to $75 \%$ CMP release, in both milk samples. Because this change is related to a deviation from hard sphere interactions and to an increase in long-range attractive forces (Sandra and Dalgleish, 2007), the similarity between the 2 systems indicated that the overall surface properties of the SM were not affected by dialysis. In addition, the hydrodynamic radius showed a similar sharp increase for both SM and $\operatorname{SM}(\mathrm{D})$ around 54 min (Figure 3B, Table 1), again demonstrating the unchanged renneting properties of the casein micelles because of dialysis.

These results were confirmed by peripheral SDSPAGE experiments (results not shown) on soluble proteins obtained by centrifugation, which showed no differences in the profiles of SM and SM(D).

Figure 4 summarizes the gelation behavior for SM and SM with added $\mathrm{CaCl}_{2}$, either directly or after $24 \mathrm{~h}$ 
Table 1. Gelation parameters ${ }^{1}$ measured during rennet coagulation of the different samples

\begin{tabular}{|c|c|c|c|c|c|c|c|}
\hline Sample $^{2}$ & $\begin{array}{c}\text { Initial 1/1* } \\
\left(\mathrm{mm}^{-1}\right)\end{array}$ & $\begin{array}{l}\text { Initial } \\
\text { radius } \\
(\mathrm{nm})\end{array}$ & $\begin{array}{l}\text { Time of } \\
\text { increase in } \\
1 / 1^{*}(\min )\end{array}$ & $\begin{array}{c}\text { Time of } \\
\text { increase in } \\
\text { radius (min) }\end{array}$ & $\begin{array}{c}\text { Gel point } \\
\text { (rheology) } \\
\tan \delta=1\end{array}$ & $\begin{array}{c}\mathrm{G}^{\prime} \text { after } \\
45 \mathrm{~min} \\
(\mathrm{~Pa})\end{array}$ & $\begin{array}{c}\tan \delta \\
\text { value at } \\
\text { plateau }\end{array}$ \\
\hline SM (control) & $1.1 \pm 0.1$ & $100 \pm 2$ & $20 \pm 1$ & $55 \pm 2$ & $53 \pm 3$ & $13 \pm 2$ & $0.264 \pm 0.002$ \\
\hline $\mathrm{SM}(\mathrm{D})$ & $1.3 \pm 0.1$ & $107 \pm 5$ & $21 \pm 1$ & $54 \pm 1$ & $54 \pm 2$ & $13 \pm 1$ & $0.263 \pm 0.001$ \\
\hline $\mathrm{SM}+\mathrm{CaCl}_{2}(t=0)$ & $1.2 \pm 0.2$ & $94 \pm 1$ & $16 \pm 1$ & $35 \pm 1$ & $32 \pm 2$ & $33 \pm 2$ & $0.252 \pm 0.001$ \\
\hline $\mathrm{SM}+\mathrm{CaCl}_{2}(t=24)$ & $1.2 \pm 0.1$ & $92 \pm 4$ & $17 \pm 2$ & $38 \pm 2$ & $39 \pm 6$ & $30 \pm 3$ & $0.254 \pm 0.001$ \\
\hline $\mathrm{SM}(\mathrm{D})+\mathrm{CaCl}_{2}$ & $1.2 \pm 0.1$ & $100 \pm 6$ & $17 \pm 1$ & $36 \pm 1$ & $34 \pm 2$ & $32 \pm 1$ & $0.253 \pm 0.001$ \\
\hline
\end{tabular}

${ }^{1}$ Initial turbidity parameter $\left(1 / 1^{*}\right)$, initial radius, time of $1 / 1^{*}$ increase, time of increase in radius, measured by diffusing wave spectroscopy; and gelation time (defined as $\tan \delta=1$ ), elastic modulus $\left(\mathrm{G}^{\prime}\right)$ measured after $45 \mathrm{~min}$ from gelation point, and plateau value of tan $\delta$. Values are averages of 3 runs with their standard deviation.

${ }^{2} \mathrm{SM}=$ skim milk; $\mathrm{SM}(\mathrm{D})=$ dialyzed $\mathrm{SM} ; \mathrm{SM}+\mathrm{CaCl}_{2}(t=0)=\mathrm{SM}$ within 30 min of direct addition of Ca; $\mathrm{SM}+\mathrm{CaCl}_{2}(t=24)=\mathrm{SM}$ within $24 \mathrm{~h}$ of direct addition of $\mathrm{Ca} ; \mathrm{SM}(\mathrm{D})+\mathrm{CaCl}_{2}=\mathrm{SM}$ with $\mathrm{Ca}$ added by dialysis.

re-equilibration or dialysis. The changes in tan $\delta$ clearly showed the difference in the gelation times (defined as $\tan \delta=1$ ) between milk with and without calcium (Figure 4A). The gelation times were shorter for milk

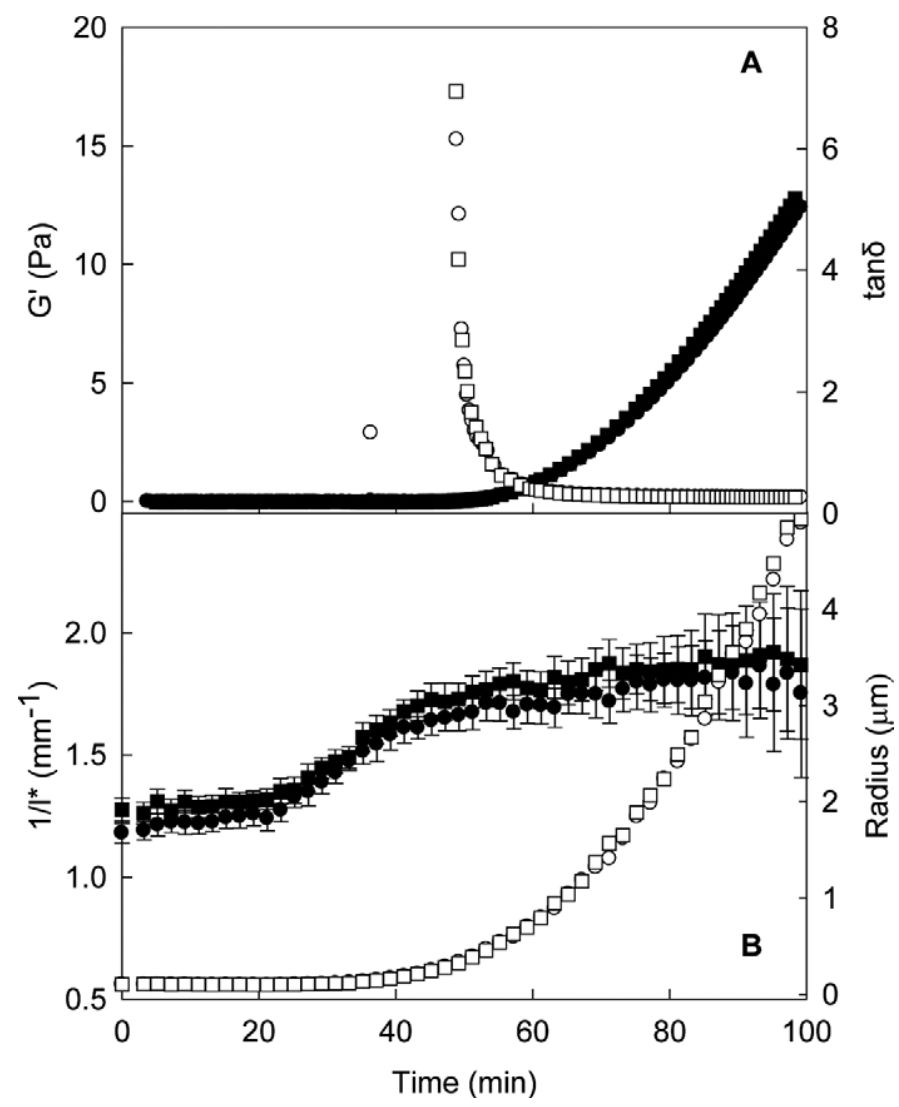

Figure 3. Development of rheology and diffusing wave spectroscopy parameters as a function of time after the addition of rennet for skim milk (SM; circles) and dialyzed SM (squares). (A) Elastic modulus, $\mathrm{G}^{\prime}$ (closed symbols) and loss tangent (tan $\delta$; open symbols); (B) turbidity parameter (1/1*; closed symbols) and apparent hydrodynamic radius (open symbols). Results are representative runs. The error bars for turbidity represent the intensity deviation from the mean used to calculate $1 / 1^{*}$ (see text). samples with added calcium than for those without calcium, as expected. Addition of $\mathrm{Ca}^{2+}$ increased the activity and concentration of ionic calcium in solution, decreasing the coagulation time by about $15 \mathrm{~min}$, in agreement with previous literature (Udabage et al., 2000, 2001). The viscoelastic properties of the ensuing gel were also affected by the addition of $\mathrm{CaCl}_{2}$. The gel modulus developed faster and more than doubled for the milk + calcium systems when measured $45 \mathrm{~min}$ after gelation (Figure $4 \mathrm{~B}$ ). The $\mathrm{G}^{\prime}$ after $45 \mathrm{~min}$ in $\mathrm{SM}$ or $\mathrm{SM}(\mathrm{D})$ was $13 \mathrm{~Pa}$, and with the addition of calcium, the values nearly doubled, ranging between 30 and 33 $\mathrm{Pa}$, irrespective of the manner of the addition (see also Table 1).

The effect of calcium has been attributed to the reduction in overall $\zeta$-potential of casein micelles, hence the reduction in electrostatic repulsion and an increase in the bonds between the casein micelles (Choi et al., 2007; Udabage et al., 1998, 2001). No significant differences were found in the manner in which the calcium was added to milk or in the time of equilibration, as all samples showed comparable $\mathrm{G}^{\prime}$ values (Table 1 ). These results are also in agreement with results obtained by Pires et al. (1999) for reconstituted skim milk powder measured $2 \mathrm{~h}$ after direct calcium addition. However, the viscoelastic properties did differ in gels prepared with and without calcium (Table 1 and Figure 5). The value of $\tan \delta$ at plateau was statistically significantly higher for SM and SM(D) compared with the values measured in the samples containing an additional 1 $\mathrm{m} M \mathrm{CaCl}_{2}$, suggesting fewer rearrangements for the samples with additional calcium. In addition, although the linear viscoelastic range for the gels did not vary between treatments (data not shown), the frequency dependence of the casein gels was significantly different between $\mathrm{SM}$ and $\mathrm{SM}+\mathrm{Ca}$, irrespective of the manner of addition. Figure 5 shows the average values of $\mathrm{G}^{\prime}$ and $\mathrm{G}^{\prime \prime}$ as a function of frequency measured $45 \mathrm{~min}$ from the gelation point; all the gels with $1 \mathrm{~m} M$ calcium 


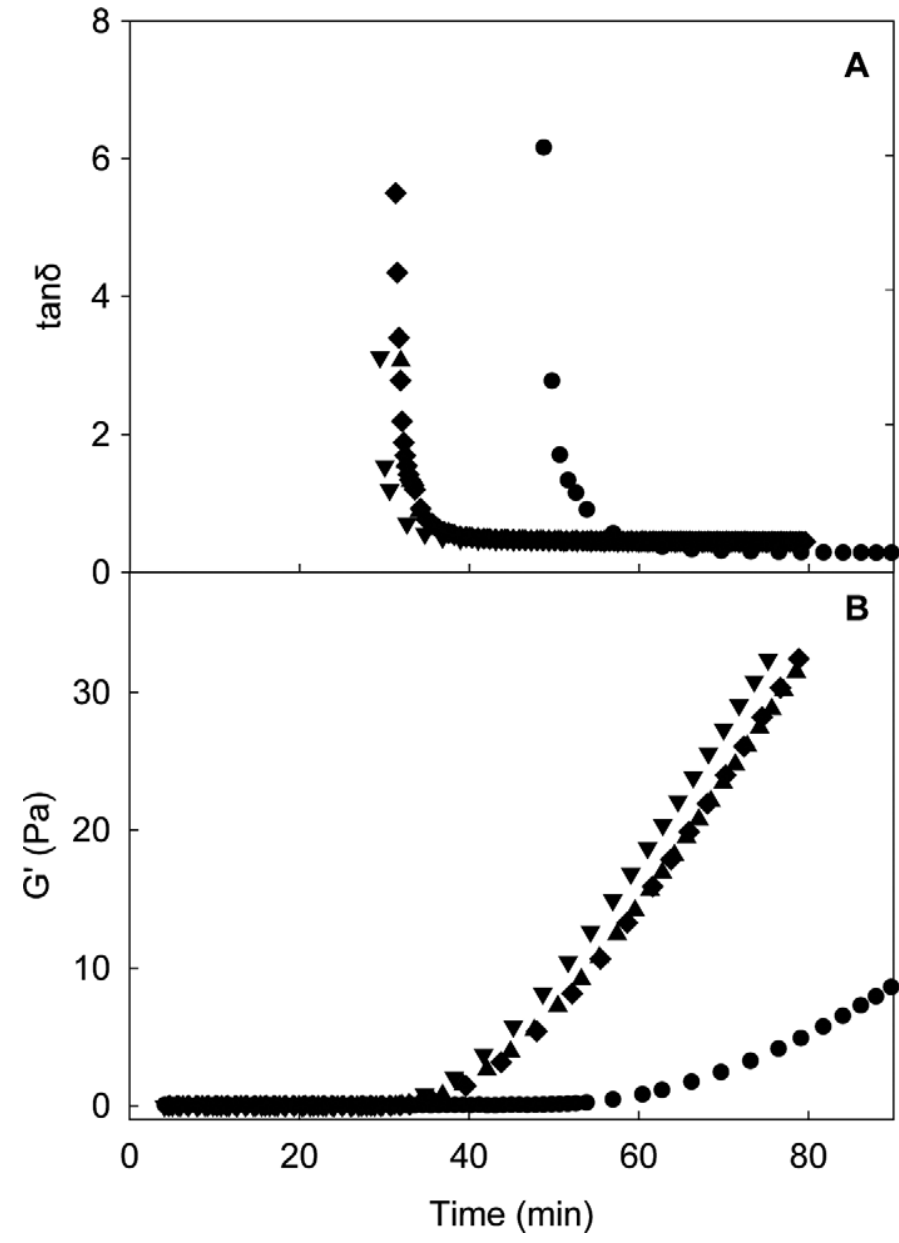

Figure 4. Development of the rheology parameters $\tan \delta(\mathrm{A})$ and elastic modulus $\left(\mathrm{G}^{\prime} ; \mathrm{B}\right)$ for control skim milk (SM; circles). SM with directly added calcium (at time $=0$, triangles; at time $=24 \mathrm{~h}$, inverted triangles) or $\mathrm{Ca}$ added by dialysis (diamonds). Results are representative runs.

added showed a lower slope of $\log \mathrm{G}^{\prime}$ as a function of $\log$ frequency. In particular, the gels with direct addition of calcium $[\mathrm{SM}+\mathrm{Ca}(t=0)]$ showed a slope of $0.141 \pm 0.006$, and that of $\mathrm{SM}+\mathrm{Ca}(\mathrm{D})$ showed a slope of $0.142 \pm 0.001$. In both cases, these values were significantly lower than in SM $(0.176 \pm 0.001)$. This may suggest that a higher extent of cross-linking because of the calcium bridging in the $\mathrm{SM}+\mathrm{Ca}$ gels.

Figure 6 illustrates the changes in the turbidity parameter and the radius during the preliminary stages of aggregation. The initial value of the turbidity parameters of $\mathrm{SM}$ or $\mathrm{SM}+\mathrm{Ca}$ did not differ (Table 1), regardless of the mode of addition of $\mathrm{CaCl}_{2}$. These results were in contrast with what reported by Philippe et al. (2003), who showed an increase in milk lightness and turbidity and no change in average casein micelle size. Figure $6 \mathrm{~A}$ summarizes the development of $1 / 1^{*}$ as a function of renneting time. The upturn of $1 / 1^{*}$ for milk samples with calcium at around 16 to 17 min (see Table 1) was earlier than for milk samples without calcium. It is interesting that the amplitude of the deviation from the average $1 / 1^{*}$ value (as shown by the error bars in the $1 / 1^{*}$ plot) increased dramatically from the control milk to the milk + calcium systems. The standard deviation shown by the turbidity plot is related to the spatial homogeneity of the system. These results may suggest that addition of calcium creates stiffer but also more compact, scattered domains after the sol-gel transition on the way to a fully developed gel. These results, in conjunction with those obtained by rheology (Figure 5), demonstrated the different type of network formed by the caseins when more calcium bridges were present between the renneted particles.

An earlier gelation point was noted in the development of the radius over time (Figure 6B), and in particular, in the rate of change of the apparent radius after the gelation point. It is important to note that DWS measures mobility rather than size, and the faster rate of increase implies a faster arrest in the motion of the caseins as they become part of the gel network. The method by which calcium was added (either directly into the milk or by dialysis) did not affect the casein coagulation process as measured by DWS.

To better understand the reasons behind the earlier upturn of the $1 / 1^{*}$ parameter and gelation point in $\mathrm{SM}+\mathrm{Ca}$ samples, the $1 / 1^{*}$ and $\mathrm{G}^{\prime}$ values were plotted as a function of the amount of CMP released (Figure 7 ). The $1 / 1^{*}$ of all of the milk samples, with or

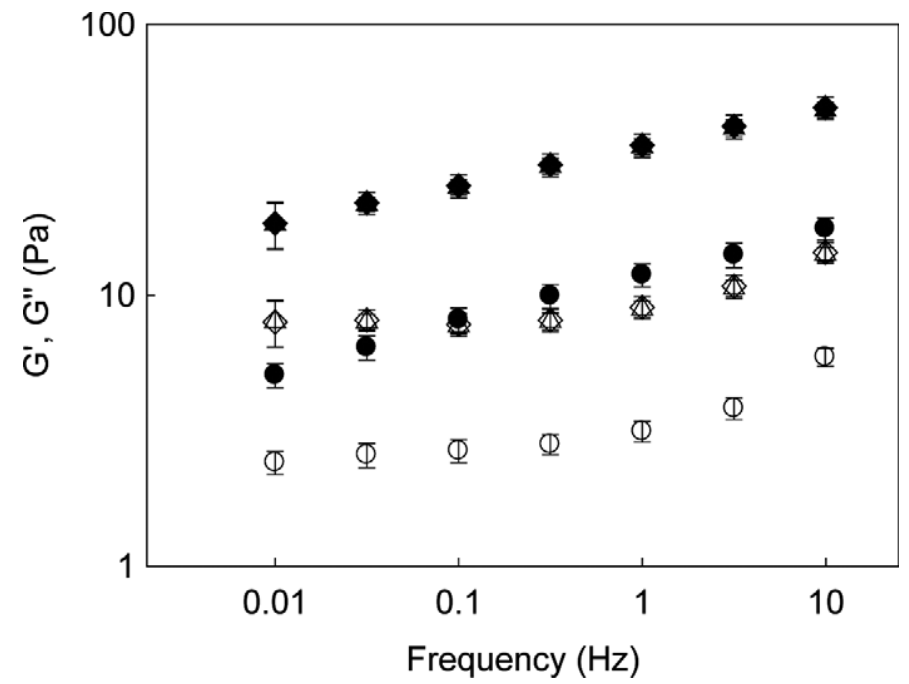

Figure 5. Frequency dependence of the elastic ( $\mathrm{G}^{\prime}$; closed symbols) and viscous ( $\mathrm{G}^{\prime \prime}$; empty symbols) moduli measured by rheology for rennet-induced gels from skim milk (SM; circles), SM with directly added calcium (triangles), and SM with $\mathrm{Ca}$ added by dialysis (diamonds). Data are average of 3 replicate runs with error bars representing standard deviation. 


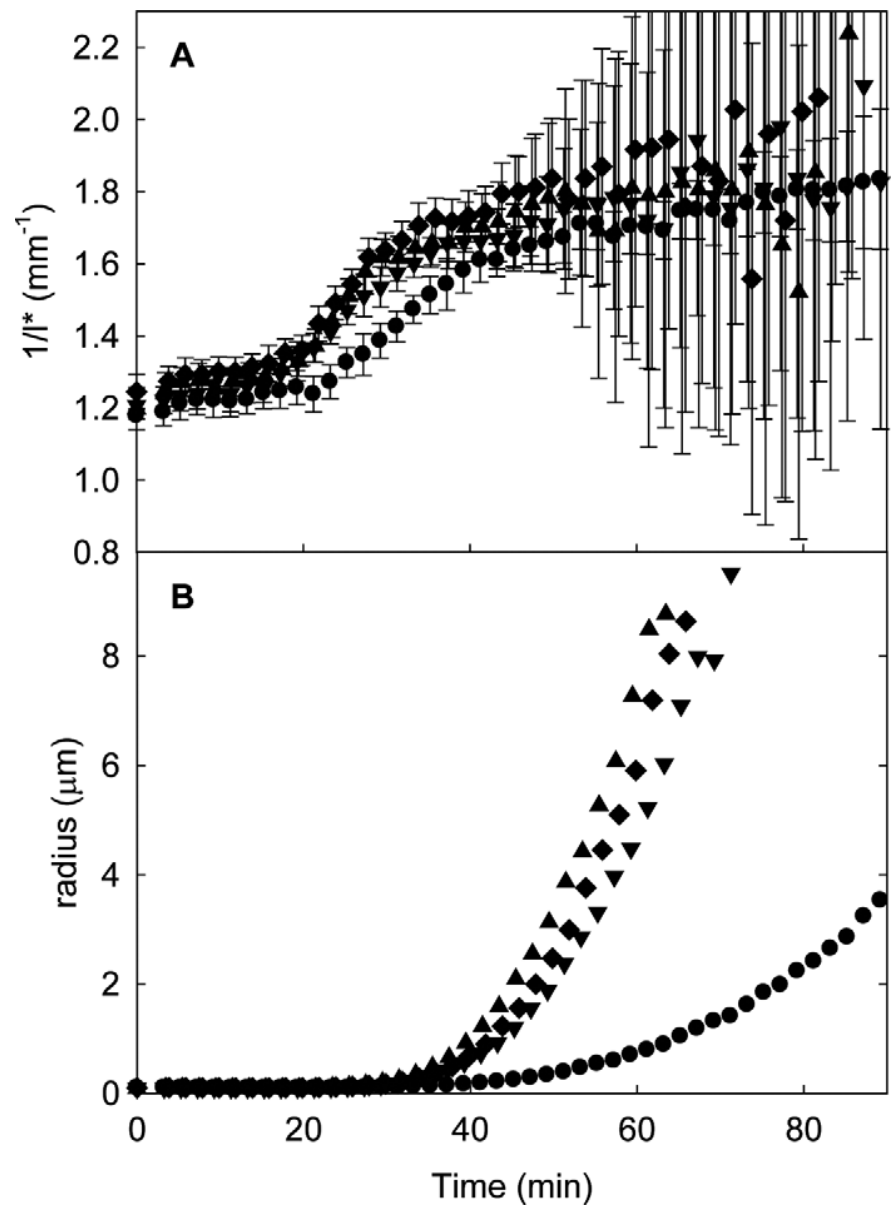

Figure 6. Development of the diffusing wave spectroscopy parameters turbidity parameter $\left(1 / 1^{*} ; \mathrm{A}\right)$ and radius $(\mathrm{B})$ as a function of time after the addition of rennet for control skim milk (SM; circles), $\mathrm{SM}$ with directly added calcium (at time $=0$, triangles; at time $=24$ $\mathrm{h}$, inverted triangles) or Ca added by dialysis (diamonds). Results are representative runs. The error bars in turbidity represent the intensity deviation from the mean used to calculate $1 / 1^{*}$ (see text).

without calcium added, started to increase rapidly at around 65 to $75 \%$ CMP release, indicating that the spatial correlations between casein micelles started to change due to the removal of hairy layer and formation of "bald patches" on the micelle surfaces (Sandra and Dalgleish, 2007). In milk with added $\mathrm{CaCl}_{2}$, the $1 / 1^{*}$ still increased at about the same level of CMP release, within experimental error. On the other hand, the rapid change in $\mathrm{G}^{\prime}$ and the gelation point of the various milk samples was different between $\mathrm{SM}$ and $\mathrm{SM}+\mathrm{Ca}$, regardless of the manner of calcium addition. The gelation in $\mathrm{SM}+\mathrm{Ca}$ corresponded to a lesser CMP release (about 85-90\% CMP release) compared with that in samples with no calcium (about $94-98 \%$ CMP release). This has previously been attributed to an increased screening of the overall charges, allowing closer approach of the partially bald micelles and more cross-linking.

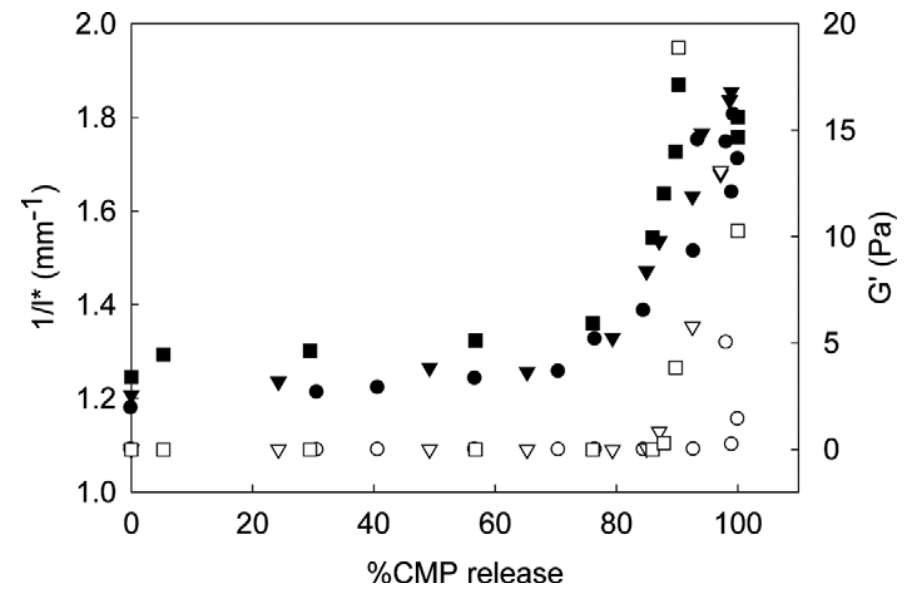

Figure 7. Development of diffusing wave spectroscopy and rheology parameters turbidity parameter $\left(1 / 1^{*}\right.$; closed symbols) and elastic modulus ( $\mathrm{G}^{\prime}$; open symbols) as a function of casein macropeptide (CMP) released from skim milk (SM; circles), SM with directly added calcium (triangles), and SM with Ca added by dialysis (diamonds). Results are representative runs.

The present results clearly demonstrate that, although close approach is not affected by the presence of additional calcium ions, the association of calcium on the surface of the micelles and increased calcium bridging play important roles in the viscoelastic properties of the gel.

\section{CONCLUSIONS}

The effect of calcium addition to the rennet coagulation properties of skim milk has been reported numerous times. Nevertheless, some discrepancies on the effect of calcium addition to each stage of rennet coagulation remain. The findings in this work confirm that the primary stage of coagulation is independent of $1 \mathrm{~m} M$ calcium addition. A minimum $\kappa$-casein cleavage is required for the micelles to initiate an increase in long-range attractive forces, and this minimum is comparable between samples with or without added calcium. On the other hand, the viscoelastic properties of the gels, as well as the gelation point and the rate of aggregation, are affected by the addition of calcium. We may conclude that calcium plays a major role in bridging between micelles, causing a downward shift in the extent of $\kappa$-casein cleavage required for gelation compared with that of milk without calcium. The rate of aggregation and the stiffness of the gels are enhanced by the addition of calcium, thus calcium addition results in gels with different viscoelastic properties. Dialysis of milk against milk does not affect the integrity of the casein micelle, as no change in amount or composition of soluble proteins is found by gel electrophoresis or in the accessibility of $\kappa$-casein to rennet action as 
shown by CMP release data. The integrity of the micelle is also not affected when calcium is added, either directly or by dialysis. As expected, the first phase of rennet coagulation is similar for both calcium-free and calcium-containing systems, but the way in which the calcium is presented to the micelles does not affect the mechanism. These results suggest that it is solely the presence or absence of ionic calcium atoms that affects rennet coagulation time and gel firmness, not the ease of availability or residence time in solution.

\section{REFERENCES}

Bringe, N. A., and J. E. Kinsella. 1986. Influence of calcium chloride on the chymosin-initiated coagulation of casein micelles. J. Dairy Res. 53:371-379.

Choi, J., D. S. Horne, and J. A. Lucey. 2007. Effect of insoluble calcium concentration on rennet coagulation properties of milk. J. Dairy Sci. 90:2612-2623.

Dalgleish, D. G. 1982. The enzymatic coagulation of milk. Page 157 in Developments in Dairy Chemistry. P. F. Fox, ed. Applied Science Publisher, London, UK.

Dalgleish, D. G. 1983. Coagulation of renneted bovine casein micelles: Dependence on temperature, calcium ion concentration and ionic strength. J. Dairy Res. 50:331-340.

Dalgleish, D. G. 1984. Measurement of electrophoretic mobilities and zeta-potentials of particles from milk using laser Doppler electrophoresis. J. Dairy Res. 51:425-438.

Dalgleish, D. G. 2011. On the structural models of bovine casein micelles-Review and possible improvements. Soft Matter 7:22652272.

De Kruif, C. G., and E. B. Zhulina. 1996. «-Casein as a polyelectrolyte brush on the surface of casein micelles. Colloids Surf. A Physicochem. Eng. Asp. 117:151-159.

Fox, P. F., T. P. Guinee, T. M. Cogan, and P. L. H. McSweeney. 2000. Fundamentals of Cheese Science. Aspen Publishers, Gaithersburg, MD.

Green, M. L., and A. S. Grandison. 1987. Secondary (non-enzymatic) phase of rennet coagulation and post coagulation phenomena. Page 97 in Cheese: Chemistry, Physics and Microbiology. P. F. Fox, ed. Elsevier App. Sci., London, UK.

Guillaume, C., S. Marchesseau, A. Lagaude, and J. L. Cuq. 2002. Effect of salt addition on the micellar composition of milk subjected to $\mathrm{pH}$ reversible $\mathrm{CO}_{2}$ acidification. J. Dairy Sci. 85:2098-2105.

Holt, C., C. G. de Kruif, R. Tuinier, and P. A. Timmins. 2003. Substructure of bovine casein micelles by small angle X-ray and neutron scattering. Colloids Surf. A Physicochem. Eng. Asp. 213:275-284.

Jen, J. J., and U. S. Ashworth. 1970. Factors influencing the curd tension of rennet-coagulated milk. Salt balance. J. Dairy Sci. 53:1201-1206.
Landfeld, A., P. Novotna, and M. Houska. 2002. Influence of the amount of rennet, calcium chloride addition, temperature, and high-pressure treatment on the course of milk coagulation. Czech J. Food Sci. 20:237-244.

Lucey, J. A., and P. F. Fox. 1993. Importance of calcium and phosphate in cheese manufacture: A review. J. Dairy Sci. 76:1714-1724.

Lucey, J. A., B. Hauth, C. Gorry, and P. F. Fox. 1993. The acid-base buffering properties of milk. Milchwissenschaft 48:268-272.

Martin, G. J. O., R. P. W. Williams, C. Choong, B. Lee, and D. E. Dunstan. 2008. Comparison of rennet gelation using raw and reconstituted skim milk. Int. Dairy J. 18:1077-1080.

Mehaia, M. A., and M. Cheryan. 1983. The secondary phase of milk coagulation: Effect of calcium, $\mathrm{pH}$ and temperature on clotting activity. Milchwissenschaft 38:137-140.

Philippe, M., F. Gaucheron, Y. Le-Graet, F. Michel, and A. Garem. 2003. Physicochemical characterization of calcium-supplemented skim milk. Lait 83:45-59.

Pires, M. S., G. A. Orellana, and C. A. Gatti. 1999. Rennet coagulation of casein micelles and heated casein micelles: Action of $\mathrm{Ca}^{2+}$ and $\mathrm{pH}$. Food Hydrocoll. 13:235-238.

Salaun, F., B. Mietton, and F. Gaucheron. 2005. Buffering capacity of dairy products. Int. Dairy J. 15:95-109.

Sandra, S., C. Cooper, M. Alexander, and M. Corredig. 2011. Coagulation properties of ultrafiltered milk retentates measured using rheology and diffusing wave spectroscopy. Food Res. 44:951-956.

Sandra, S., and D. G. Dalgleish. 2007. The effect of ultra high-pressure homogenization (UHPH) on rennet coagulation properties of unheated and heated fresh skimmed milk. Int. Dairy J. 17:10431052.

Solorza, F. J., and A. E. Bell. 1998. Effect of calcium on the minerals retention and cheesemaking parameters of milk. Int. J. Dairy Technol. 51:37-43.

Udabage, P., M. A. Augustin, and I. R. McKinnon. 1998. Effects of mineral salts on renneted milk gels. Aust. J. Dairy Technol. $53: 139$

Udabage, P., I. R. McKinnon, and M. A. Augustin. 2000. Mineral and casein equilibria in milk: Effects of added salt and calciumchelating agents. J. Dairy Res. 67:361-370.

Udabage, P., I. R. McKinnon, and M. A. Augustin. 2001. Effects of mineral salts and calcium-chelating agents on the gelation of renneted skim milk. J. Dairy Sci. 84:1569-1575.

van Hooydonk, A. C. M., H. G. Hagedoorn, and I. J. Boerrigter. 1986 The effect of various cations on the renneting of milk. Neth. Milk Dairy J. 40:369-390.

Walstra, P. 1990. On the stability of casein micelles. J. Dairy Sci. 73:1965-1979.

Weitz, D. A., and D. J. Pine. 1993. Diffusing-wave spectroscopy. Pages 652-720 in Dynamic Light Scattering: The Method and Some Applications. Oxford University Press, Oxford, UK.

Wolfschoon-Pombo, A. F. 1997. Influence on the addition of calcium chloride to milk on the cheese yield. Int. Dairy J. 7:249-254. 